\title{
A Function-Based Approach for Life Cycle Management of Chemicals in the Textile Industry
}

\author{
Sandra Roos ${ }^{1, * \mathbb{C}}$, Stefan Posner ${ }^{2}$, Christina Jönsson ${ }^{1}$, Elisabeth Olsson ${ }^{1}$, \\ Hanna Nilsson-Lindén ${ }^{1}{ }^{\circledR}$, Steffen Schellenberger ${ }^{1}$, Mikael Larsson ${ }^{1}$, Anne-Charlotte Hanning ${ }^{1}$ \\ and Rickard Arvidsson ${ }^{3}$ iD \\ 1 Division of Material and Production, RISE Research Institutes of Sweden, Box 857, 50115 Borås, Sweden; \\ christina.jonsson@ri.se (C.J.); elisabeth.olsson@ri.se (E.O.); hanna.linden@ri.se (H.N.-L.); \\ steffen.schellenberger@ri.se (S.S.); mikael.g.larsson@ri.se (M.L.); anne-charlotte.hanning@ri.se (A.-C.H.) \\ 2 Stefan Posner AB, Statskullevägen 7, 43955 Åsa, Sweden; posner.stefan@gmail.com \\ 3 Division of Environmental Systems Analysis, Chalmers University of Technology, Vera Sandbergs Allé 8, \\ 41296 Gothenburg, Sweden; rickard.arvidsson@chalmers.se \\ * Correspondence: sandra.roos@ri.se; Tel.: +46-10-228-4733
}

Received: 20 December 2019; Accepted: 8 February 2020; Published: 10 February 2020

check for updates

\begin{abstract}
Consumer products such as clothes and footwear sometimes contain chemical substances with properties that pose a risk to human health and the environment. These substances, restricted by law or company policy, are in focus for chemicals management processes by textile retailers. However, complex and non-transparent supply chains, and limited chemical knowledge, makes chemicals management challenging. Therefore, a function-based approach for life cycle management (LCM) of chemicals was developed, based on results of previous projects and evaluated using a two-step Delphi process. The resulting approach aims to help retailers identify and substitute hazardous substances in products, and consists of three parts: (i) a function-based chemicals management concept model for different levels of chemical information within the supply chain, (ii) tools for non-chemists which explain chemical information, and (iii) a continuous provision of knowledge to stakeholders (e.g., retailers) in a network. This approach is successfully implemented by over 100 retailers in the Nordic countries, providing the textile industry with practical and robust tools to manage and substitute hazardous chemicals in products and production processes. We conclude that the developed approach provides an explicit link, communication, and knowledge sharing between actors in the supply chain, which has proven important in chemicals LCM.
\end{abstract}

Keywords: life cycle management (LCM); LCM practice; chemicals management; substitution; knowledge sharing; textile; leather; retail; implementation

\section{Introduction}

Life cycle management (LCM) is intended to provide an operational discipline to produce, deliver, support, and retire product offerings in a sustainable manner, by considering the environmental aspects along the entire product life cycle [1,2]. Thus, LCM implies expanding the scope of environmental management activities from internal operations to encompass the complete product life cycle from cradle to grave [3].

For the textile value chain, the most critical environmental impacts are related to the use and emissions of toxic chemicals, and also use of water and energy [4-6]. However, complex and non-transparent supply chains, and limited chemical knowledge, makes chemicals management challenging. This paper will argue that the current LCM tools and practices are not enough to support the textile industry in the management of chemicals throughout the supply chain in a satisfactory way. 
An LCM approach for chemicals management need to be able to support substitution of hazardous chemicals with safer options, as well as improved handling of chemicals in use, and mitigation of emissions of toxic chemicals.

\subsection{Related Works}

In her review of the LCM literature, Nilsson-Lindén found that descriptions of LCM practices in the industry are rare [7]. Instead, the focus is more often on developing different methods and tools rather than contributing with experiences of using such methods and tools in practice. In addition, Seuring and Müller found in their overview of descriptions of industry practice that in several cases, such experiences are described without aiming at theory development or testing [8]. The literature on chemicals and LCM generally includes considerations such as contribution to climate change or energy use of chemical industries and chemical products $[9,10]$. However, LCM practices for retailers to manage chemicals in products are previously not described in the academic literature, nor does the academic literature describe LCM in relation to toxicity impacts and compliance with chemicals regulations. In fact, the only explicit mentioning, from 2006, is by Gloria et al. [11] who stated that, at that time, life cycle assessment (LCA) methods for metal toxicity impacts could not support practical decision-making by policy makers or business in an LCM context.

This scarcity of LCM studies considering chemicals is unexpected, since in order to adequately assess chemical substitutions, it is necessary to focus on chemicals in products, their functions, and impacts from a product life cycle perspective, as opposed to only focus on chemicals in production processes [12]. Chemicals management in the Nordic textile industry is difficult due to the long and complex supply chains that are typical for this industry, which mainly consist of companies that trade textile goods from Central and East Asia $[13,14]$. Some years back, the production of textiles, as well as textile chemicals for the European market was mainly located in Europe. The information exchange between the chemical experts and the textile processing experts could then be conducted directly on site. Today, the chemical content of products is controlled by actors that retailers have little or no direct contact with. In addition, there are linguistic barriers and cultural differences that hinder and confuse the exchange of knowledge. The chemicals management practices that today dominate among textile retailers are certification schemes [15,16], restricted substances lists (RSL) $[17,18]$, and chemicals management tools [19]. None of these approaches employ a life cycle perspective. Hence, an LCM perspective is needed where chemicals are studied as part of products, since they "travel" between actors in the product life cycle-this perspective is here referred to as "chemicals LCM".

Chemicals LCM, and LCM in general, is closely related to the area of knowledge management. Management of knowledge and information, and the sharing of such knowledge, is vital for collaborating on the variety of multifaceted environmental issues that exists along the supply chain [7]. One of the aspects proven to be important when collaborating in supply chains is the need to understand each other across language barriers. For this purpose, focus turns to explicit knowledge and the need for well-functioning instructions, guides, and tools. However, a clear focus on tacit knowledge is also needed. Tacit knowledge, referring to knowledge considered difficult to articulate in an explicit form [20], also has to be prioritized. In that sense, tools and instructions need to be combined with continuous activities for knowledge sharing.

\subsection{Background}

Despite the lack of literature on chemicals LCM, such practice has been performed as part of a collaboration including Nordic textile and leather retailers. Although these retailers experience market competition, this collaboration has been considered a fruitful approach. One of the reasons for this is that most brands do not possess deep knowledge of chemicals and their use in the textile and leather supply chains, nor information regarding the rationale behind chemicals legislation. In 2005, the collaboration was formalized as an industry network, called the Swedish Chemicals Group at RISE [21], as a joint initiative by a number of Nordic retail companies and the Swedish research 
institute RISE (former Swerea), in order to develop a practical chemicals LCM approach for non-experts in chemistry ("non-chemists"). Note that despite the term "Swedish", retailers from other Nordic countries participate as well.

\subsection{Structure of the Paper}

In this paper, we provide a detailed description of a chemicals LCM approach for the textile supply chain, developed within the network, together with the underlying function-based theory. Furthermore, we describe an evaluation of the approach made by the over 140 Nordic retailers today in the Swedish Chemicals Group. The scope of the LCM approach is chemicals management in the clothes, footwear, and home textiles sector, including textiles, leather, accessories, trims, and packaging materials. The purpose of the approach is to build capacity to meet legal and customer demands within the area of chemical compliance and substitution of hazardous substances for better alternatives (Method section). The proposed approach consists of a combination of tools, models, and educational elements, developed based on extensive experience and insights from working with textile value chains and textile brands (Results section). This is followed by a discussion on chemicals LCM related to other aspects of LCM (Discussion section) and ending with conclusions and recommendations (Conclusions section). By providing a detailed description of chemicals LCM in the textile industry, we hope to provide insight on how theory, in terms of an understanding of chemicals' functions, can be activated into the daily work and practice in the industry.

\section{Method}

\subsection{Development of the Approach}

The development of the function-based chemicals LCM approach is based on insights from the Swedish Chemicals Agency project INKA [22]. The INKA project identified that the prevailing communication around the chemical content of products was not adequate to protect consumers and/or the environment from being exposed to hazardous substances. Textile consumer products such as clothes, footwear, and home textiles generally consist of several different materials and the textile materials, in turn, contain a wide range of chemical substances [23,24]. Product labelling schemes require laboratory testing and/or audits which makes it too expensive for many companies to apply on their whole product range. A systematic approach to identifying and managing chemicals, as well as substitution possibilities was required.

The information management systems in the chemical industry have been built up around the identity of the individual chemical substances, for example, the CAS numbers provided by the Chemical Abstracts Service (CAS), a division of the American Chemical Society [25], or the EC numbers from the European Chemicals Agency [26]. The chemical industry manages a huge number of chemicals; more than 140 million different chemical substances (with CAS numbers) are known as of today [25]. The practical applications for each substance are various and the chemicals manufacturers seldom have the full overview of all possible downstream applications that exist for their products. However, for "non-chemists", the CAS number of a chemical substance will not always be meaningful information. Hence, the information systems based on the identity of a chemical substance do not always suit the downstream users in the textile supply chain. Moreover, the communication regarding chemical substances in the supply chain of chemical products is generally limited to hazardous substances for which safety data sheets (SDS) are required and substances regulated at the time. When chemical substances are turned into materials or products, information about the content of chemical substances and chemicals used in upstream processes is generally not communicated [27]. For suppliers of products, it is rather the function provided by the chemical, for example, water and soil repellency, UV stabilization and colour, which is discussed in the communication with the subcontractors. The chemical industry (generally chemistry experts) and the textile industry (generally non-chemists) simply do not use the same language when they communicate. 
This insight led the authors to develop a function-based chemicals management concept model for supply chain communication together with the Nordic textile retailers, which later became one of three parts of a chemicals LCM approach (see Section 3.1). The concept model builds on defining different categories of chemicals depending on the reason (the function) behind their presence in a certain material or product. Three main categories of chemicals may be distinguished: (1) Product function chemicals; (2) process function chemicals, and (3) background level contamination chemicals. These categories are described in Table 1, together with examples and suggestions for how to manage the chemicals. As a general rule, product function chemicals are present in high concentrations, since there is typically a threshold value under which the concentration is too low to provide any function [28]. Of course, many chemicals are multi-functional and can provide different functions to a material or a product. Process function chemicals are added to enable production processes. If they remain in the finished products after the process, they are considered impurities. The presence of process function chemicals and raw materials related chemicals is, in contrast to background level contamination chemicals, possible to predict and control by the process specification. Hence, this relates to the best available technology (BAT).

Table 1. Categorization of chemicals occurring in textile and leather products using the function-based chemicals management concept model.

\begin{tabular}{|c|c|c|c|}
\hline Category & Description & Examples & Management Possibilities \\
\hline $\begin{array}{l}\text { Product function } \\
\text { chemicals }\end{array}$ & $\begin{array}{l}\text { Provide a desired property to the end product } \\
\text { (colour, soft hand, reduced odour, etc.). The } \\
\text { chemicals are produced by humans or nature } \\
\text { and intentionally added to the product. They } \\
\text { are often detected in high concentrations in the } \\
\text { end product. }\end{array}$ & $\begin{array}{l}\text { Dyestuffs/pigments, } \\
\text { water repellent agents, } \\
\text { softeners, plasticizers, } \\
\text { flame retardants, } \\
\text { biocides. }\end{array}$ & $\begin{array}{l}\text { Specify the desired chemistry } \\
\text { to reach the desired technical } \\
\text { properties of the end product } \\
\text { to the supplier. }\end{array}$ \\
\hline $\begin{array}{l}\text { Process function } \\
\text { chemicals }\end{array}$ & $\begin{array}{l}\text { Provide a desired property to the process } \\
\text { (processability, increased yield etc.) or are raw } \\
\text { materials. The chemicals are produced by } \\
\text { humans or nature and intentionally added to } \\
\text { the process. They are seldom detected in high } \\
\text { concentrations in the end product. }\end{array}$ & $\begin{array}{l}\text { Catalysts, cross-linking } \\
\text { agents, solvents, } \\
\text { lubricants, release agents, } \\
\text { foaming agents, } \\
\text { monomers. }\end{array}$ & $\begin{array}{l}\text { Secure good operating } \\
\text { practices. For chemicals that } \\
\text { are not possible to separate } \\
\text { from the end product: Specify } \\
\text { the desired chemistry to the } \\
\text { supplier. }\end{array}$ \\
\hline $\begin{array}{c}\text { Background level } \\
\text { contamination chemicals }\end{array}$ & $\begin{array}{l}\text { Chemicals that occur through unintended } \\
\text { production by humans or nature. They enter } \\
\text { products and processes as impurities. They are } \\
\text { seldom detected in high concentrations in the } \\
\text { end product. }\end{array}$ & $\begin{array}{l}\text { Heavy metals, persistent } \\
\text { organic pollutants. }\end{array}$ & $\begin{array}{l}\text { Secure good operating } \\
\text { practices and use of } \\
\text { high-quality input chemicals } \\
\text { and non-contaminated } \\
\text { resources. }\end{array}$ \\
\hline
\end{tabular}

As will be described in Section 3.2, an important component of the approach is the ChemicAll database, which contains textile-relevant chemical substances that have been classified by authorities as hazardous and/or are questionable due to information from non-official sources such as non-governmental organizations (NGOs). This database constitutes the informational backbone of the approach. ChemicAll was created at the research institute RISE to simplify storage of and access to all the information gathered about chemicals in textiles. Based on a plethora of data sources, such as the scientific literature, regulatory background reports and information from the participating companies, a compilation of textile-relevant chemicals, their functional properties, and applicable materials has been made and is continuously improved and updated. The knowledge is stored in the database and refined into the different hands-on tools for practical application in the daily work performed by the retailers-see, e.g., Sections 3.2.2 and 3.2.3.

The concept model and the hands-on tools provide together the common ground for the third component of the approach, the continuous knowledge provision supplied via the network called the Swedish Chemicals Group at RISE, where today over 100 retailers in the Nordic countries participate.

\subsection{Evaluation of the Approach}

As part of the development of the function-based chemicals LCM approach, a structured evaluation was conducted within the network, using a two-step Delphi process [29]. In the first step, a list of 
candidates for success factors was created from the authors' own assumptions based on the feedback given during the years together with eight success factors described by Nilsson-Lindén [7]. Furthermore, within a larger email survey to the network members, they were asked to state the three most important reasons why the network was valuable to their organisation, which was considered a criterion for being a success factor. The email survey resulted in 48 different statements of "value". There was a certain overlap between these statements and those originating from the authors and the literature. Therefore, the members' statements were sorted into groups of statements that covered the same success factor. A set of 17 candidate success factors was finally extracted. In the second step, the 17 candidates were presented at a network meeting with ca 120 participants and a closed voting was performed in order to identify the "top" value statements. All participants could select maximum three different value statements to vote for. The value statements, their origin, and the voting results are shown in the Results section.

\section{Results}

The function-based chemicals LCM approach consists of three distinct parts (Figure 1):

- Function-based chemicals management concept model (theory).

- Chemicals LCM tools for non-chemists (tools).

- Continuous knowledge provision (human resources).

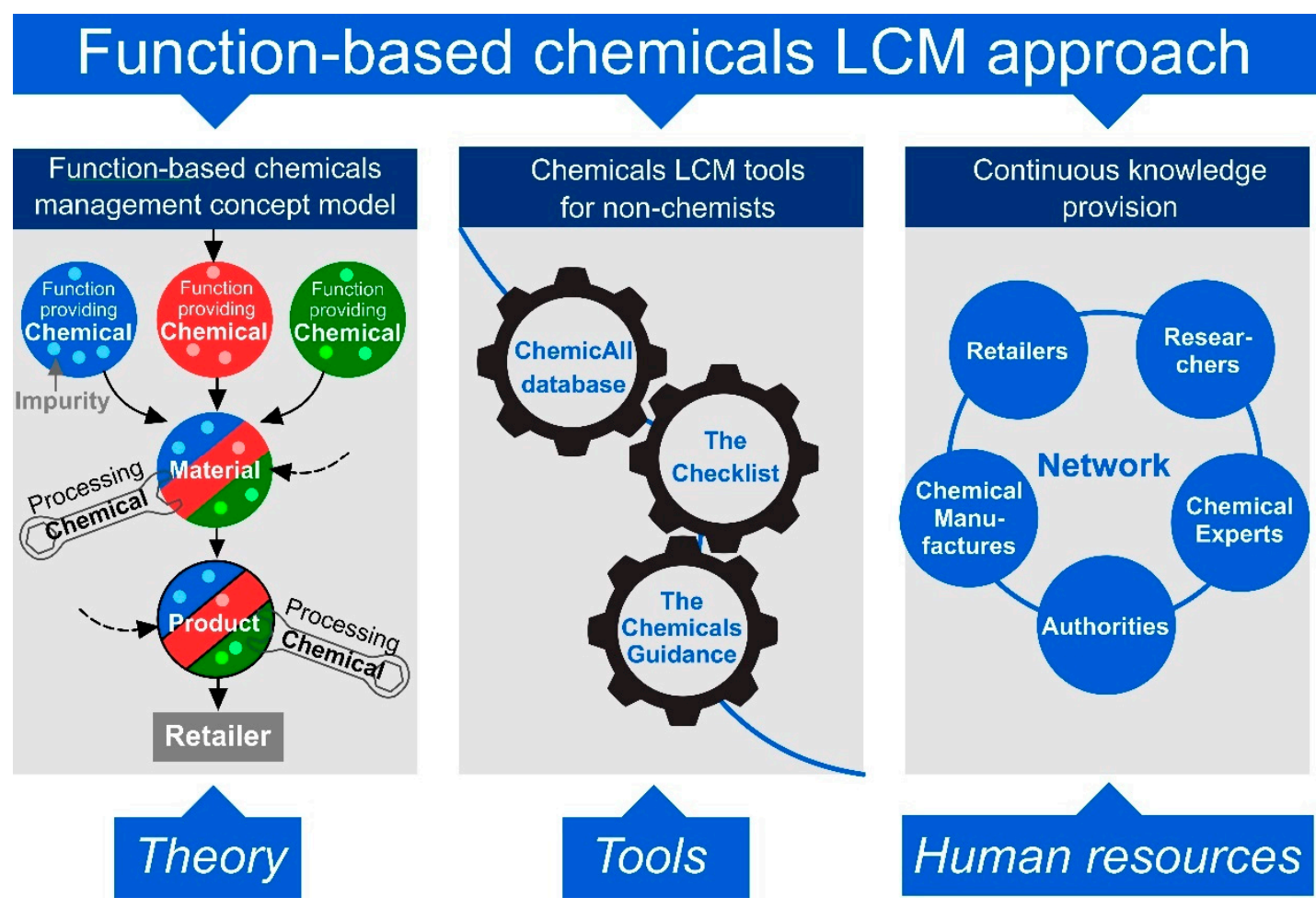

Figure 1. The function-based chemicals life cycle management (LCM) approach consists of three parts: Theory, tools, and human resources.

These three parts are described below in Sections 3.1-3.3.

\subsection{Function-Based Chemicals Management Concept Model}

The concept model of the function-based chemicals LCM approach is based on the information available at different levels in a textile supply chain, see Figure 2. The supply chain actors (retailers, 
suppliers, sub-suppliers, and raw material suppliers) all have knowledge related to the chemicals content in the textile products, but on different levels.

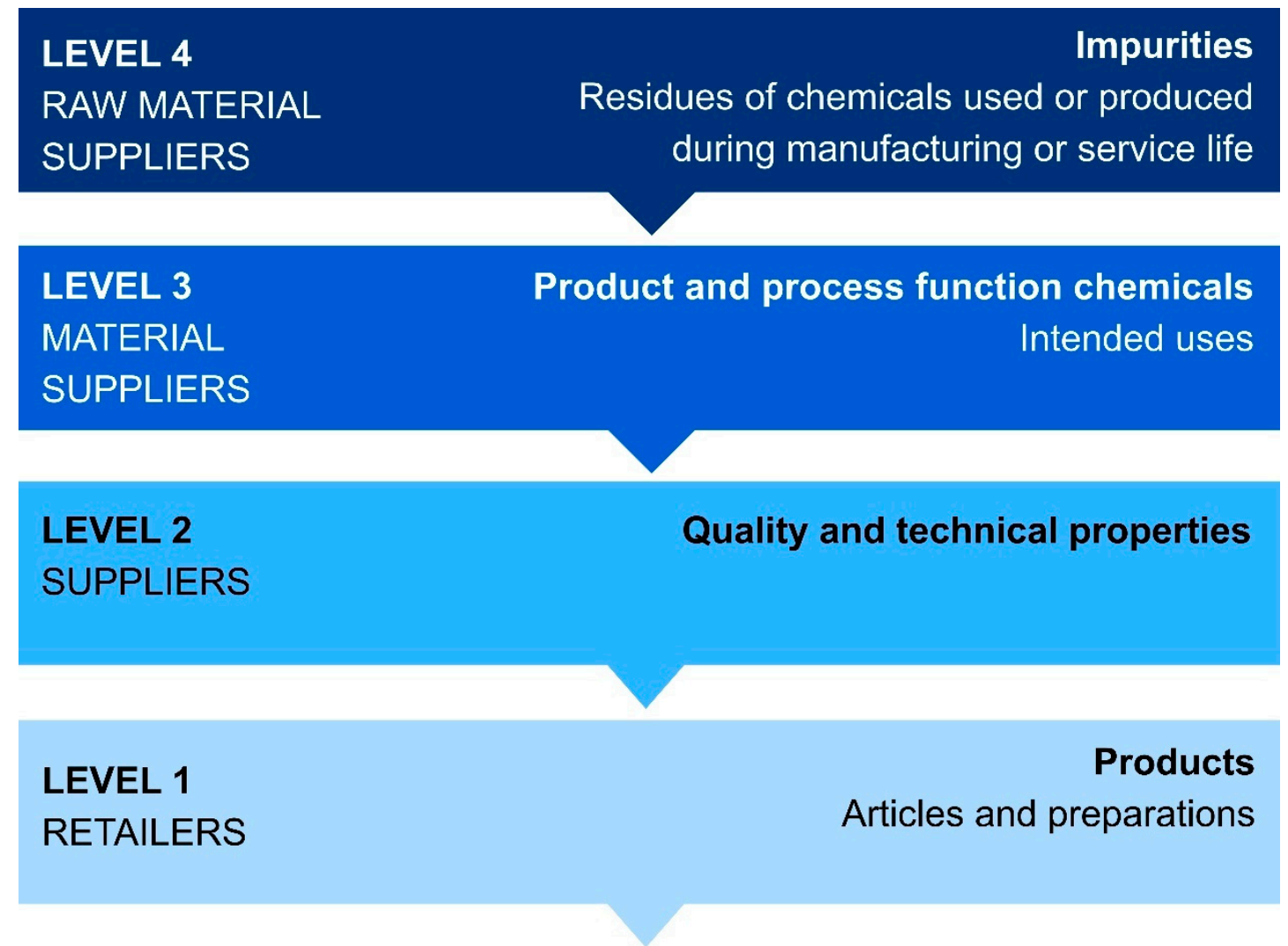

Figure 2. The concept model of the function-based chemicals LCM approach.

The first level involves retailers, i.e., producers or importers of products, which is the level at which many legal requirements are set. Level two consists of suppliers (sewing factories/garment makers), which most often ensures the quality and technical properties of the products. These properties are sometimes specified by the retailers, but quite often the full specification is made by suppliers. The supplier will deliver a product that complies with all retailer demands but otherwise is as cost effective as possible. At the third level in the model the sub-suppliers (fabric maker/dye house) are found who decide which chemicals are to be applied to achieve the quality and technical properties (product function chemicals in Table 1). This information is seldom communicated downstream the supply chain due to business secrets. At this level, where application of chemicals to a material occurs, processes are often conducted at large-scale, where one batch of material is produced to fit several customers and the selection of process function chemicals is made. The fourth level represents the raw material supplier (chemicals manufacturer/fibre supplier) where the quality management of both chemicals and raw materials will ultimately determine the content of impurities later on in the end product.

Moreover, today's development of circular materials makes textile and leather retailers seek to understand opportunities both to use secondary (recycled) raw materials, as well as design materials for recyclability. In the first case, there is a need to evaluate what chemistry has been used in the supply chain and what chemicals may be present due to the history of the secondary raw material. In the second case, information about chemical content is important from two aspects: (i) If there are chemicals present that may pose legal risks and (ii) if there are chemicals present that may negatively affect the recycling efficiency. Thus, circularity becomes an important part of the chemicals management program and ways to control compliance. 


\subsection{Chemicals LCM Tools for "Non-Chemists"}

Below, the three major tools used for implementation of the chemicals LCM approach are described: The ChemicAll Database, the Chemicals Guidance, and the Checklist. In addition, there are several other tools developed, including a template for how to write legal contracts, as well as guidance documents for how to order laboratory testing and interpret laboratory test protocols. Such additional tools are of great importance since it is often difficult to communicate the requirements related to legal aspects when the receiver of the demand (for example, a supplier outside the EU) does not have to comply with the same legislation as the sender. In such cases, contracts, restriction lists, and a transparent dialogue are key.

The tools described below cover all components of clothes, footwear, and home textiles, including textile materials, leather, accessories in metal, plastics, rubber, etc. and finally also packaging materials.

\subsubsection{The ChemicAll Database}

ChemicAll is a database for textile/leather-relevant chemicals that have been classified by authorities as hazardous and/or are questionable due to information from other reliable but non-official sources such as non-governmental organizations (NGOs) and academic literature. The information about chemical substances in materials is searchable also if the substance identity (CAS RN, EC number, IUPAC name, etc.) is not known, but the quality and technical requirements are known, in other words the function, see Figure 3. In this way, ChemicAll is a chemicals database that requires minimal chemistry competence from the user. The user can choose different product characteristics, such as the different materials in a textile article, and receive a list of the unwanted chemicals that are commonly occurring in these specific materials. The user can also search the database for quality and technical properties, or choose to combine these two options, for example by searching for flame retardants in polyester fibres. Another alternative can be to combine a characteristic or property with legal information, and for example find out which plasticizers for polyvinylchloride (PVC) are restricted in different countries. The database also contains information about known substitutes, both in terms of different chemistry and different material choice, to facilitate substitution of the unwanted chemicals. Recommended substitutes are chemicals that are known to be less harmful while providing the desired function or property.

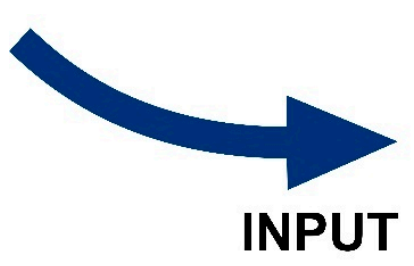

$$
\begin{aligned}
& \text { Product characteristics } \\
& \text { Quality and technical } \\
& \text { properties } \\
& \text { Legal, company policy, } \\
& \text { voluntary schemes etc }
\end{aligned}
$$

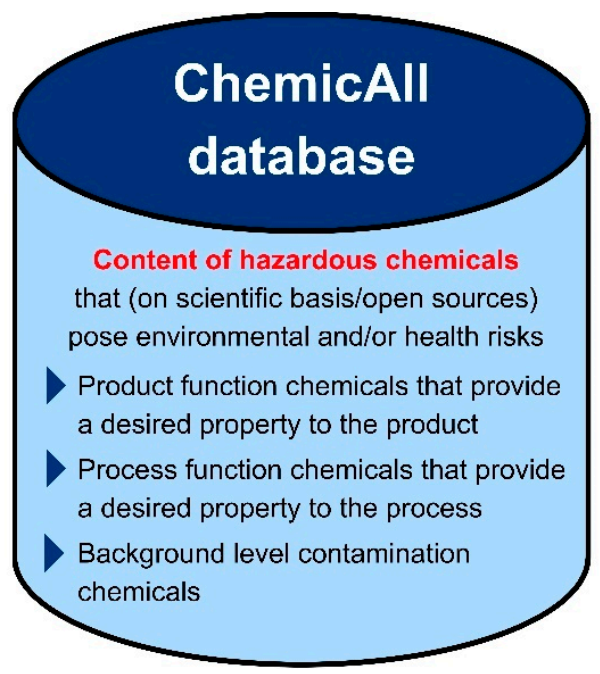

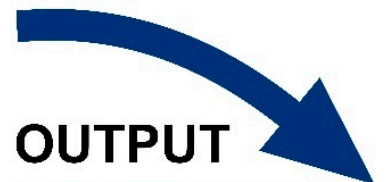

List of hazardous / unwanted chemicals sorted by input, chemical characteristics, legal information and possible substitutes

Figure 3. Inputs (query) and outputs of the ChemicAll database.

Currently, only members of the Swedish Chemicals Group have access to the database, as it is partly built up on confidential information from the member companies, and dependent on a membership funding mechanism to become updated and retain its value. 


\subsubsection{The Chemicals Guidance}

"The Chemicals Guidance" is a document developed to facilitate importers of textile and leather goods to the EU to comply with the chemicals legislation in force. The Chemicals Guidance contains a digested set of textile/leather-relevant and regulated chemicals from the ChemicAll database, where the relevance for supply chain control has been identified using the function-based chemicals LCM approach. The distinguishing properties of the chemicals and the processes in which they are used are described in the Chemicals Guidance. The guidance document also stipulates test equipment commonly occurring, and the limits of quantification (LOQ) that are generally accepted. The guide also includes recommendations regarding chemicals or processes to be used instead of the unwanted chemicals.

The Chemicals Guidance replaces the traditional way of chemicals management in the textile supply chain, which is to send the supplier a long list of substances that should not occur in the product, an RSL, whereof the main part may be entirely irrelevant for textile products. The length of such lists makes the task of controlling all these substances impracticable and may lead to the supplier taking no action at all. The Chemicals Guidance instead supports communication in the supply chain around the most commonly occurring unwanted chemicals for each material and thereby simplifies decision-making for the supplier. It is used today by the whole spectrum of professions in the textile retail industry, from product developers, designers, purchasers to chemists.

\subsubsection{The Checklist}

The Checklist is a tool especially developed to simplify communication in the supply chain between customers and suppliers that have an established relationship. Many suppliers receive the entire Chemicals Guidance (described above) as specification for the chemical requirements for each product and each order. The Chemicals Guidance is relevant for textile and leather goods in general, however, for a specific product or product type, even further digestion can be made using the function-based chemicals LCM approach. The Checklist provides a simplified overview of the product requirement for a certain order, an extract is shown in Figure 4.

Product / Product group Oktober 2019(p1/3)

\begin{tabular}{|c|c|c|}
\hline Material/design/functionality/process/targeted chemicals & $\begin{array}{r}\text { NN } \\
\text { limit } \\
\text { value }\end{array}$ & $\begin{array}{r}\text { EU legal requirement } \\
\left(\mathbf{m g} / \mathbf{k g}^{\mathbf{1}}\right) \\
\text { The listed substance is } \\
\text { restricted in REACH annex } \\
\text { XVII if nothing else is } \\
\text { written. }\end{array}$ \\
\hline \multicolumn{3}{|l|}{$\square$ Dyed cellulosic fibers such as cotton, hemp, flux, viscose etc. } \\
\hline - Banned arylamines derived from azo dyes & & 30 \\
\hline - Carcinogenic dyestuffs and pigments incl. quinoline & & $\begin{array}{r}50{\text { (quinoline })^{2}}^{2} \\
1000 \text { (candidate list) }^{\text {cand }}\end{array}$ \\
\hline \multicolumn{3}{|l|}{$\begin{array}{l}\square \text { Dyed synthetic fibers (polyester, acetate, triacetate, polyamide, PVC), } \\
\text { natural fibers (wool, silk) and leather }\end{array}$} \\
\hline - Banned arylamines derived from azo dyes & & 30 \\
\hline - Carcinogenic dyestuffs and pigments incl. quinoline & & $\begin{array}{r}50{\text { (quinoline })^{2}}^{2} \\
1000 \text { (candidate list) }^{\text {cand }}\end{array}$ \\
\hline - Allergenic disperse dyes and Navy Blue & & 1000 (Navy Blue) \\
\hline - Chlorinated benzenes and toluenes (carriers) ${ }^{3}$ & & \\
\hline
\end{tabular}

Figure 4. Extraction of the Checklist (cut-out from a three-page long document) for simplified communication of high-risk chemicals in specific product or product types, version October 2019.

A practical example of usability is when a textile trader has no knowledge of which chemicals are important to consider in a jacket. The trader does, however, have good knowledge of the various 
materials in a jacket. Based on the particular material qualities and the jacket design, it is possible to extract a list of relevant hazardous chemicals for that particular jacket. For example, the type of fibre decides the type of dyestuff, and thereby the non-relevant dyestuff for the specific product can be excluded from the risk list. The Checklist is also commonly used internally in companies to communicate the selection of products for which random samples will be sent to laboratory testing. Note that the Checklist is limited to high-risk chemicals and does not substitute the Chemicals Guidance.

\subsection{Continuous Knowledge Provision via Networking}

The networking and knowledge sharing between researchers and companies in the Swedish Chemicals Group is the third key component of the function-based chemicals LCM approach. In addition to the chemicals LCM tools, the network offers a discussion platform that provides monitoring and updated information via both seminars and individual support. The network is international and includes, apart from the retailer members, other factors such as chemicals manufacturers, authorities, labelling, and voluntary schemes and is led by a group of researchers and chemicals experts. Since the start of the network in 2005, the collaborative approach has led to a recognized capacity building of competence in the area of hazardous substances in textiles [27,30-33]. The continuous knowledge provision via networking is vital for the approach to keep its relevance. The legislation on, and recommendations for, content of chemicals in textile products are consistently changing. Background documents to legislations such as REACH [34], the Biocidal Products Regulation (BPR) [35], and the POP regulation [36] and their amendments are per se a source of knowledge about the possible content of hazardous chemicals in textile products. Involvement of the experts in the Swedish Chemicals Group in the execution of research commissions for authorities has led to the fact that insights concerning industrial relevance in combination with expert knowledge could be created and continue to be used within the network $[23,30,37,38]$. Moreover, parallel work in research projects such as POPFREE [39], ENFIRO [40] and Mistra Future Fashion [40,41], and SUPFES [42] is an important source for knowledge provision. The database ChemicAll has been used as a curated knowledge reservoir, with an information structure aimed at simplifying access to the information for "non-chemists".

The network enables the researchers to understand the industrial reality and provide continuous improvement of the services from the network, and from the company's side, meetings enable access to the chemicals' knowledge base. The spoken language does also have importance and therefore it has been a deliberate choice to keep the conversation in the group in Swedish as far as possible and translate the information given from international expertise into Swedish. The importance of the spoken language is equally important in the supply chain, therefore the central tools such as the Chemicals Guidance is also available in Chinese, Vietnamese, Turkish, and Bengali, on request by the member companies.

The possibility for "non-chemists" to communicate chemical information is regarded as one of the key merits of the developed approach by the authors. The personnel in the textile industry have responsibilities and competences that range from product developers, designers, purchasers to chemists. In the open and vivid discussion climate in the network format, they all contribute to making the information clear and understandable.

\subsection{Results from the Evaluation of the Approach}

As part of the continuous improvement of the function-based chemicals LCM approach, a structured evaluation of the value of the approach was performed (see method for details about the method used). The results show that the value statements that received the highest ranking by the network members relate to support regarding highly practical issues, such as keeping up to date with regulations and other developments, as well as receiving support regarding advanced issues in chemicals management (Figure 5). The responsible person for chemicals management in a company usually only works part-time with this task and divides her or his time between other tasks, such as quality management and/or social compliance. Considering the limited time spent, it is difficult to 
ensure fulfilment of legal and customer demands, let alone taking proactive steps in this field. Being supported by a well-established approach provides the opportunity to being both compliant and able to take proactive action.

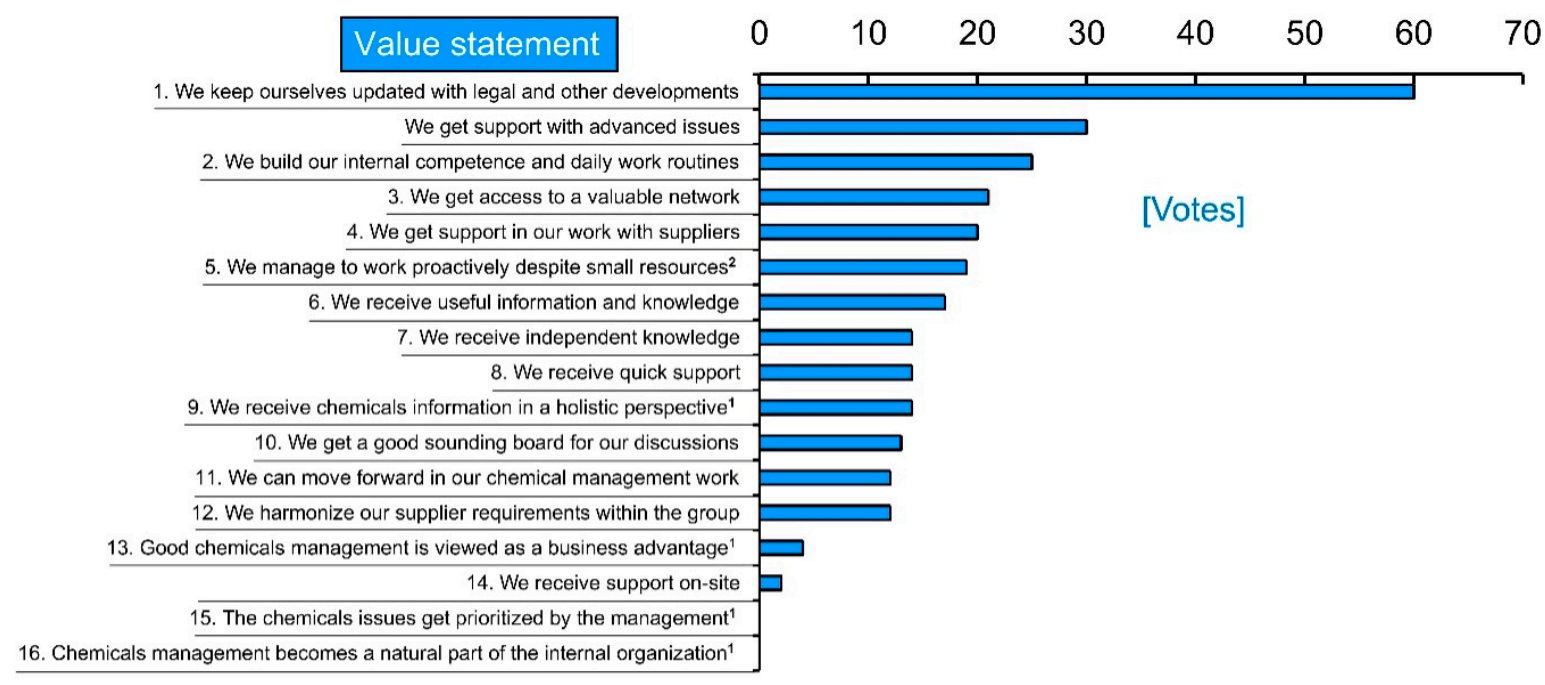

Figure 5. Results of the second step of the member-based evaluation of the function-based chemicals LCM approach. ${ }^{1}$ Additions based on [7]. ${ }^{2}$ Additions based on own observations.

The third most appreciated value was that the member companies can build internal competence and daily work routines. Making chemicals information understandable for the people in the textile retail business will increase their competence in procurement and product development. The ability to put sound requirements on chemical content and check-up procedures will make the procurer less vulnerable to unknowingly receiving low-quality goods. Competence in interpreting laboratory test protocols correctly will increase the confidence that the promised properties have been delivered. The procurer will not have to solely rely on the supplier's recommendations but can question facts about, for example, the possibilities of substituting a substance. Sometimes it is possible to substitute the desired property of a chemical substance with physical or mechanical means, for example, by choosing a completely different material. A supplier of the old solution might not suggest such an option as it would mean that the company moves to a competitor, and instead such discussions must be taken on the product design level. Thus, the function-based chemicals LCM approach offers the textile company a way to work actively with continuous capacity building concerning improvement of the chemical performance of their products.

\section{Discussion}

The Swedish Chemicals Group and its tools have been described as good examples of chemicals LCM by external parties. The ChemicAll database was ranked top 10 in an overview of tools for chemicals management and substitution of hazardous chemicals by the OECD [43]. ChemicAll was also highlighted in a UNEP study on management of chemicals in products as "a practical example of a tool designed to help designers and purchasers make informed decisions and carry on an informed dialogue with their suppliers on the subject of chemicals present in their final products" [32]. The UNEP report further pointed to ChemicAll's outstanding property: That information about chemicals in textile materials is searchable also if the substance identity is not known, but the quality and technical requirements are known, realized by the function-based chemicals LCM approach. Furthermore, the network as such has been mentioned as a good example in practice by several authors $[27,31,33]$.

Another important aspect is that databases and tools must be continuously updated to reflect current knowledge and regulation. For practical reasons, this requires continuous financing of some sort. Providing information and tools for free is in theory ethically commendable. However, in a 
context where both the legislation and knowledge are rapidly increasing, information and tools will soon become outdated and funding for updates is generally difficult to find. In the described approach, the financing is shared between the industry partners in the form of membership fees, and the research institute, in the form of research projects and commissions, which has proven to be a feasible financial model for continuous maintenance and development.

The function-based chemicals LCM approach contains several components that are recommended in the LCM literature. Nilsson-Lindén et al. [44] found, when examining LCM literature, several factors that were often deemed essential for organizations to work successfully with LCM. These critical success factors were listed as:

1. Top management support,

2. communication and interaction,

3. integration across functions,

4. part of everyday practice,

5. alignment with business strategy,

6. knowledge of LCM,

7. holistic environmental approach, and

8. collaboration of product chain actors.

In particular, factors 2, 4, and 8 are easily identified as components of the function-based chemicals LCM approach. It is more difficult to find direct evidence of the occurrence of elements of the other success factors, which can be considered room for future improvements.

The function-based chemicals LCM approach is also sector-based, focusing on the textile and leather value chains, which was identified as a success factor for uptake of LCM by small and medium-sized enterprises (SMEs) by Seidel-Sterzik et al. [45]. However, the disadvantages of a sector-based approach to LCM, as opposed to individual organisations implementing LCM, include the loss of first-mover advantage and time-consuming cooperation processes. In case of the above-described approach, one of the major advantages is building capacity for following the chemicals legislation and customer requirements, thus the target group is not so sensitive to the loss of first-mover advantage.

A striking difference between the function-based approach for chemicals LCM and the LCM models that Seidel-Sterzik et al. investigated is that the latter are all documents, without any link to support in the daily business, such as network activities or similar [2,46,47].

Uptake and acceptance of sustainability practices has been identified before as a key factor for success [48]. The fact that tools and knowledge are developed and used within a network building a long-term relationship is likely to support uptake and use of the approach, which in turn supports continuous improvement of tools and assurance that the information is relevant and updated. The long-term relationships between researchers and companies offer the possibility for deepened understanding, from the researcher's side, of industrial practices, and, from the company's side, of chemicals information. The value of such "coaching" is also one of the cornerstones for implementation of lean production management in companies, a comparable knowledge management philosophy [49,50]. Moreover, Börjeson et al. [33] stated that networking in general is found to be a success factor and explicitly mentioned the Swedish Chemicals Group.

Compared with the general descriptions of LCM systems in McLaren and McLaren [3], the function-based approach for chemicals LCM has a limited scope. However, for SMEs, a clear and limited scope can be seen as an advantage. According to McLaren and McLaren [3], implementing an LCM programme involves consideration of organisational aspects, selection of internal LCM project areas, and external communication. With the function-based chemicals LCM approach, new members have access to examples on how existing member companies have organized the work and results can be used directly to provide answers to customers' requirements. 


\section{Conclusions}

This paper provides a detailed example of implementation of a function-based chemicals LCM approach by Nordic textile and leather retailers from theory to practice. As such, it adds to the body of research on LCM practices and provides a description of chemicals LCM, which is otherwise largely lacking in the scientific literature. The most important part of the implementation of the LCM practices is to establish the missing link between the chemical industry and the textile industry with the help of function-based tools, platforms for knowledge sharing, and help overcome language barriers. The concept model of the function-based chemicals LCM approach (Figure 2) offers an explicit link between, on the one hand, the quality and technical properties of a product that are specified by the retailers, and on the other hand, the chemicals used in the supply chain, and therefore enables retailers to control the latter.

The function-based chemicals LCM approach was developed to be a practical and robust tool, for daily use by "non-chemists" in textile retail companies and is based on scientific information, as well as continuous improvement of the communication around chemicals in the textile supply chain. The advantages are improved quality of the goods, less laboratory testing for regulatory compliance, and reduction of both economic and legal risks. Based on the experience from working with the implementation of these LCM practices in the Nordic textile industry, we provide the following recommendations for successful chemicals LCM:

1. Continuity. Databases and tools must be continuously updated to reflect current knowledge and regulation.

2. Funding. For practical reasons, continuous knowledge provision via networking requires continuous financing of some sort. In this approach, the financing is shared between the industry, in the form of membership fees, and the research institute, in the form of research projects and commissions.

3. Knowledge at the appropriate detail level. Some factors understand and require deep and detailed knowledge related to chemicals and their impacts. Other factors may only require and be able to grasp basic knowledge due to time restraint or educational background. The three different LCM tools developed (the ChemicAll database, the Chemicals Guidance, and the Checklist) allow for such an adaption to different knowledge needs.

4. Coaching. The long-term relationships between researchers and companies offers the possibility for deepened understanding of the industrial reality and continuous improvement of the services provided by the network from the researcher's side, and from the company's side, of the chemical information.

Although these recommendations are provided based on the LCM work conducted for the Nordic textile industry, we hypothesize that they may hold some generality and relevance also to other regions, as well as other industries and product groups.

Author Contributions: Conceptualization, S.P., S.R., R.A., E.O., and C.J.; writing-original draft preparation, S.R., E.O., C.J., and H.N.-L.; writing-review and editing, R.A., S.P., A.-C.H., S.S., and M.L.; visualization, S.S.; supervision, R.A. All authors have read and agreed to the published version of the manuscript.

Funding: This research was funded by Swedish funding agencies Mistra and Formas in the Mistra Future Fashion program and the SUPFES project, respectively, as well as funding from RISE and XPRES (Initiative for Excellence in Production Research), which is greatly acknowledged.

Acknowledgments: We would like to thank the members of the Swedish Chemicals Group at RISE for their invaluable contribution during the first fifteen years of the network.

Conflicts of Interest: The authors declare no conflict of interest. 


\section{References}

1. Moreno, O.A.V.; Swarr, T.E.; Asselin, A.-C.; Milà i Canals, L.; Colley, T.; Valdivia, S. Implementation of life cycle management practices in a cluster of companies in Bogota, Colombia. Int. J. Life Cycle Assess. 2015, 20, 723-730. [CrossRef]

2. Remmen, A. Life Cycle Management: A Business Guide to Sustainability; UNEP/Earthprint: Paris, France, 2007.

3. McLaren, J.; McLaren, S. Life Cycle Management. In Hatched: The Capacity for Sustainable Development; Frame, B., Gordon, R., Mortimer, C., Eds.; UNLV: Las Vegas, NV, USA, 2010.

4. Allwood, J.M.; Laursen, S.E.; Rodriguez, C.M.; Bocken, N.M.P. Well Dressed? The Present and Future Sustainability of Clothing and Textiles in the United Kingdom; Institute for Manufacturing, University of Cambridge: Cambridge, UK, 2006; ISBN 1-902546-52-0.

5. European Commission. Integrated Pollution Prevention and Control (IPPC) Reference Document on Best Available Techniques for the Textiles Industry; European IPPC Bureau: Seville, Spain, 2003.

6. Roos, S. Towards Sustainable Use of Chemicals in the Textile Industry: How Life Cycle Assessment can Contribute; Chalmers University of Technology: Gothenburg, Sweden, 2015.

7. Nilsson-Lindén, H. A Knowledge Management Perspective on Environmental Life Cycle Management A Manufacturing Company Example; Chalmers University of Technology: Gothenburg, Sweden, 2014; Available online: http://publications.lib.chalmers.se/records/fulltext/197631/197631.pdf (accessed on 4 February 2020).

8. Seuring, S.; Müller, M. From a literature review to a conceptual framework for sustainable supply chain management. J. Clean. Prod. 2008, 16, 1699-1710. [CrossRef]

9. Chemical lifecycle management. Available online: https://www.chemengonline.com/chemical-lifecyclemanagement (accessed on 10 February 2020).

10. Biswas, G.; Clift, R.; Davis, G.; Ehrenfeld, J.; Förster, R.; Jolliet, O.; Knoepfel, I.; Luterbachcr, U.; Russell, D.; Hunkeler, D. Ecometrics. Int. J. Life Cycle Assess. 1998, 3, 184-190. [CrossRef]

11. Gloria, T.; Russell, A.; Atherton, J.; Baker, S.; Cook, M. Ecological Toxicity Methods and Metals. An examination of two case studies (8 pp + 1). Int. J. Life Cycle Assess. 2006, 11, 26-33. [CrossRef]

12. Jönsson, C.; Posner, S.; Roos, S. Sustainable Chemicals: A Model for Practical Substitution. In The Detox Fashion- Cleaning Up Fashion Sector; Muthu, S.S., Ed.; Springer: Singapore, 2018; ISBN 978-981-10-4875-3.

13. Fransson, K.; Molander, S. Handling chemical risk information in international textile supply chains. J. Environ. Plan. Manag. 2013, 56, 345-361. [CrossRef]

14. Kogg, B. Responsibility in the Supply Chain Interorganisational Management of Environmental and Social Aspects in the Supply Chain Case Studies from the Textile Sector; IIIEE, Lund University: Lund, Sweden, 2009; ISBN 9789188902467.

15. BLUESIGN@. Available online: http://www.bluesign.com/ (accessed on 13 December 2019).

16. STANDARD 100 by OEKO-TEX®. Available online: https://www.oeko-tex.com/en/our-standards/standard100-by-oeko-tex (accessed on 13 December 2019).

17. AAFA Restricted Substance List. Available online: https://www.aafaglobal.org/AAFA/Solutions_Pages/ Restricted_Substance_List.aspx (accessed on 13 December 2019).

18. Roadmap to Zero. Available online: http://www.roadmaptozero.com/ (accessed on 13 December 2019).

19. AFIRM Supplier Chemistry Toolkit. Available online: http://www.afirm-group.com/toolkit/ (accessed on 6 December 2019).

20. Hislop, D. Knowledge Management in Organizations: A Critical Introduction; Oxford University Press: New York, NY, USA, 2005.

21. The Chemicals Group. Available online: https://www.ri.se/en/what-we-do/networks/chemicals-group? refdom=www.swerea.se (accessed on 13 December 2019).

22. Swedish Chemicals Agency. KemI rapport 6/04-information om varors Innehåll av farliga kemiska ämnen; Swedish Chemicals Agency: Sundbyberg, Sweden, 2004.

23. Olsson, E.; Posner, S.; Roos, S.; Wilson, K. Kartläggning av kemikalieanvändning i kläder; Swerea IVF AB: Mölndal, Sweden, 2009.

24. Poulsen, P.B.; Schmidt, A.; Nielsen, K.D. Kortlægning af kemiske stoffer i tekstiler; Danish Environmental Protection Agency: Copenhagen, Denmark, 2011.

25. CAS REGISTRY. Available online: http://www.cas.org/content/chemical-substances (accessed on 10 February 2020). 
26. C\&L Inventory. Available online: https://echa.europa.eu/information-on-chemicals/cl-inventory-database (accessed on 10 February 2020).

27. Fransson, K. Chemical Risk Information in Product Chains. The Cases of Paint and Textiles. Licentiate Thesis, Chalmers University of Technology, Gothenburg, Sweden, 2012.

28. Posner, S.; Olsson, E.; Jönsson, C.; Roos, S. Literature Survey of Chemicals in Toys; Swerea IVF AB: Mölndal, Sweden, 2012.

29. Linstone, H.A.; Turoff, M. The Delphi Method-Techniques and Applications, 2nd ed.; Addison-Wesley Educational Publishers Inc: London, UK, 2002; pp. 1-616.

30. Strömbom, S.; Posner, S.; Roos, S.; Jönsson, C. Chemicals management in the textile sector-Dialogue between authorities, research institutes and retailers leading to concrete actions. In Proceedings of the 7th International Conference on Life Cycle Management, Bourdeaux, France, 30 August-2 September 2015; p. 631.

31. Reihlen, A.; Halliday, R. Scientific and Technical Support for Collecting Information on and Reviewing Available Tools to Track Hazardous Substances in Articles with a View to Improve the Implementation and Enforcement of Article 33 of REACH; Publications Office of the European Union: Luxembourg, 2017.

32. Munn, K. The Chemicals in Products Project: Case Study of the Textiles Sector; United Nations Environmental Program, DTIE/Chemicals Branch: Geneva, Switzerland, 2011.

33. Börjeson, N.; Gilek, M.; Karlsson, M. Knowledge challenges for responsible supply chain management of chemicals in textiles-As experienced by procuring organisations. J. Clean. Prod. 2014, 107, 130-136. [CrossRef]

34. European Commission. Regulation (EC) No 1907/2006 of the European Parliament and the Council of 18 December 2006 concerning the Registration, Evaluation, Authorisation and Restriction of Chemicals (REACH), establishing a European Chemicals Agency, amending Directive 1999/45/E. Off. J. Eur. Union 2006, L396, 0001-0851.

35. European Commission. Regulation (EU) No 528/2012 of the European Parliament and of the Council of 22 May 2012 concerning the making available on the market and use of biocidal products. Off. J. Eur. Union 2012, 167, 1-123.

36. Corrigendum to Regulation (EC) No 850/2004 of the European Parliament and of the Council of 29 April 2004 on persistent organic pollutants and amending Directive 79/117/EEC. Off. J. Eur. Union 2004, 229, 5-22.

37. Kara, H.; Sengstschmid, H.; Posner, S. A Study to Facilitate the Implementation of the Waste Related Provisions of Regulation (EC) No 850/2004 on Persistent Organic Pollutants; Department for Environment, Food and Rural Affairs: London, UK, 2010.

38. Posner, S. Polyfluorinated Chemicals and Transformation Products. In Handbook of Environmental Chemistry; Knepper, T.P., Ed.; Springer: Heidelberg, Sweden, 2011.

39. POPFREE-Promotion of PFAS-free Alternatives. Available online: https://www.ri.se/en/what-we-do/projects/ popfree-promotion-pfas-free-alternatives (accessed on 10 February 2020).

40. Leonards, P. Life Cycle Assessment of Environment-Compatible Flame Retardants (Prototypical Case Study), ENFIRO. NORMAN Netw. Ref. Lab. Monit. Emerg. Environ. Pollut. New Bull. 2011, 2, 1-20.

41. Roos, S.; Posner, S.; Jönsson, C.; Peters, G.M.G.M.; Jönsson, C.; Peters, G.M.G.M. Is unbleached cotton better than bleached? Exploring the limits of life cycle assessment in the textile sector. Cloth. Text. Res. J. 2015, 33, 231-247. [CrossRef]

42. Schellenberger, S.; Holmquist, H.M.; Berger, U.; Cousins, I.T.; Gillgard, P.; Leonards, P.; Peters, G.; Posner, S.; van der Veew, I.; Weiss, J.; et al. Substitution of long chain fluorinated copolymers for durable water repellent (DWR) textile modification. In Proceedings of the Society of Environmental Toxicology and Chemistry (SETAC)| SETAC Europe, 25th Annual Meeting, Barcelona, Spain, 3-7 May 2015.

43. OECD Substitution and Alternatives Assessment Toolbox. Available online: www.oecdsaatoolbox.org/ (accessed on 10 February 2020).

44. Nilsson-Lindén, H.; Baumann, H.; Rosén, M.; Diedrich, A. Organizing life cycle management in practice: challenges of a multinational manufacturing corporation. Int. J. Life Cycle Assess. 2018, 23, 1368-1382. [CrossRef]

45. Seidel-Sterzik, H.; McLaren, S.; Garnevska, E. Effective life cycle management in SMEs: Use of a sector-based approach to overcome barriers. Sustainability 2018, 10, 359. [CrossRef]

46. Remmen, A.; Jensen, A.; Frydendal, J. A business guide to sustainability. In Life Cycle Management; UNEP: Paris, France, 2007. 
47. Remmen, A. An Introduction to Life-Cycle Thinking and Management; The Danish Ministry of the Environment: Copenhagen, Denmark, 2003.

48. Horne, R.E. Limits to labels: The role of eco-labels in the assessment of product sustainability and routes to sustainable consumption. Int. J. Consum. Stud. 2009, 33, 175-182. [CrossRef]

49. Liker, J. The Toyota Way: 14 Management Principles from the World's Greatest Manufacturer, 1st ed.; McGraw-Hill: New York, NY, USA, 2003; ISBN 0-07-139231-9.

50. Achanga, P.; Shehab, E.; Roy, R.; Nelder, G. Critical success factors for lean implementation within SMEs. J. Manuf. Technol. Manag. 2006, 17, 460-471. [CrossRef]

(C) 2020 by the authors. Licensee MDPI, Basel, Switzerland. This article is an open access article distributed under the terms and conditions of the Creative Commons Attribution (CC BY) license (http://creativecommons.org/licenses/by/4.0/). 